ORIGINAL ARTICLES

\title{
Permanent pacemaker insertion in a district general hospital: indications, patient characteristics, and complications
}

\author{
A Eltrafi, P Currie, J H Silas
}

\begin{abstract}
This report reviews the experience of permanent pacemaker insertion in a district general hospital (catchment population of 350000 ) and makes a comparison with the national database and other hospitals in the UK.

Methods-The records of all patients receiving a permanent pacemaker in the inclusive period January 1996 to December 1998 were reviewed. Data collected included number of patients paced each year, age, sex, indications, and complications.

Results-In the three years reviewed 200 patients received new permanent pacemakers, a rate of 190 per million population per year, which is similar to the national implantation rate of permanent pacemakers but lower than that of most European countries (see discussion). The majority of patients paced were elderly ( $75 \%$ were above the age of 70 years).

Atrioventricular block (including complete heart block, $45 \%$, and Mobitz type 2 block, $12.5 \%$ ) was the commonest indication for permanent pacemaker insertion, followed by sick sinus syndrome $(25 \%)$ and these findings are comparable to those reported previously. However, carotid sinus syndrome was responsible for $16 \%$ of the patients paced and this was higher than that reported in the national database $(6.5 \%)$. Only $1 \%$ of the pacemaker modes used was inappropriate and the complication rate was low at $3 \%$.

Conclusions-This report confirms that permanent pacemaker insertion can be effectively and safely provided locally for the increasingly ageing population. The implantation rate both locally and nationally is still much lower than that of some countries in Europe.

(Postgrad Med F 2000;76:337-339)
\end{abstract}

Keywords: permanent pacemaker; atrioventricular block; sick sinus syndrome; carotid sinus syndrome

In 1987 the working group of the British Cardiac Society endorsed the view that permanent cardiac pacing can be effectively performed in district general hospitals ${ }^{1}$; by 1992 one third of hospitals in the UK provided this service. ${ }^{2}$ This is becoming more important nowadays as the number of elderly patients is increasing and it is more convenient for this service to be provided locally. In this study a three year experience of a district general hospital serving a population of 350000 is reported.

The aim of this study was to report a district general hospital experience in performing permanent pacemaker insertion and to compare it with that reported from a similar population and that of the national database.

\section{Methods}

The records of the patients who had had permanent pacemakers in the inclusive period of January 1996 to December 1998 were reviewed.

The permanent pacemaker insertion was performed in the cardiac catheter laboratory by one of two teams: each comprised a consultant cardiologist, a specialist registrar, a cardiac technician, a cardiac nurse, and a radiographer.

Prophylactic antibiotics (flucloxacillin $1 \mathrm{~g}$ or clindamycin $600 \mathrm{mg}$ ) were given intravenously routinely before permanent pacemaker insertion and continued orally (fluocloxacillin 500 mg four times a day or clindamycin $300 \mathrm{mg}$ four times a day) for 48 hours afterwards. The procedure was performed under local anaesthetic. The subclavian vein route was used for pacemaker insertion in most patients but one of the consultants used the cephalic vein if it was appropriate. Chest radiography was performed and the pacemaker was checked before discharge from hospital. Subsequent follow up was technician based with input from doctors when required.

\section{Results}

NUMBER AND CHARACTERISTICS OF PATIENTS PACED

In the 36 months studied, 200 patients with an age range of $31-95$ years ( $75 \%$ of patients were more than 70 years old) were paced. Of these $107(53.5 \%)$ were males (age range 52-95 years). The overall implantation rate was 190 per million population per year.

INDICATIONS FOR PACING AND THE MODES USED Appendix 1 explains the five letter code description of the pacemaker mode adopted by North American and British Group and appendix 2 describes the general guidelines and principles used for permanent pacemaker insertion. 
Table 1 Pacemaker modes used compared with those recommended by the British Pacing and Electrophysiology Group ${ }^{4}$

\begin{tabular}{|c|c|c|c|c|}
\hline Common indications & $\begin{array}{l}\text { Modes used } \\
\text { and number }\end{array}$ & $\begin{array}{l}\text { Optimal modes } \\
\text { recommended }\end{array}$ & $\begin{array}{l}\text { Alternative } \\
\text { modes }\end{array}$ & $\begin{array}{l}\text { Inappropriate } \\
\text { modes }\end{array}$ \\
\hline CAVB and Mobitz type 2 & $\begin{array}{l}\mathrm{DDD}=113 \\
\mathrm{VVI}=2\end{array}$ & DDD & VDD & $\begin{array}{l}\text { AAI } \\
\text { DDI }\end{array}$ \\
\hline SSS without AVB & $\begin{array}{l}\mathrm{AAIR}=9 \\
\mathrm{AAI}=12\end{array}$ & AAIR & AAI & $\begin{array}{l}\text { VVI } \\
\text { VDD }\end{array}$ \\
\hline SSS with AVB & $\begin{array}{l}\mathrm{DDD}=22 \\
\mathrm{DDDR}=3 \\
\mathrm{DDI}=2 \\
\mathrm{VVI}=2\end{array}$ & $\begin{array}{l}\text { DDDR } \\
\text { DDIR }\end{array}$ & $\begin{array}{l}\text { DDD } \\
\text { DDI }\end{array}$ & $\begin{array}{l}\text { AAI } \\
\text { VVI }\end{array}$ \\
\hline CSS & $\begin{array}{l}\text { DDI }=17 \\
\text { DDD }=12 \\
\text { VVI }=1 \\
\text { DDDR }=2\end{array}$ & DDI & $\begin{array}{l}\text { DDD } \\
\text { VVI }\end{array}$ & $\begin{array}{l}\text { AAI } \\
\text { VDD }\end{array}$ \\
\hline
\end{tabular}

NB. The optimal mode of pacing should be considered for most patients. The alternative mode is acceptable for patients who have intermittent symptoms or who have a short life expectancy because of another disease. ${ }^{4}$

$\mathrm{AVB}=$ atrioventricular block; $\mathrm{CAVB}=$ complete atrioventricular block; CSS = carotid sinus syndrome; SSS = sick sinus syndrome.

The total number of patients in this table is 197. The details of the three others were not known.

Complete atrioventricular block was the commonest (90 patients; $45 \%$ ) indication for permanent pacemaker insertion followed by sick sinus syndrome ( 50 patients; $25 \%$ ), carotid sinus syndrome (32 patients; $16 \%$ ) and Mobitz type $2(25 ; 12.5 \%)$.

Table 1 shows the modes used compared with the modes currently recommended by the task force of the American College of Cardiology and American Heart Association ${ }^{3}$ and adopted by British Pacing and Electrophysiology Group (BPEG). ${ }^{4}$ Of the 115 patients who had atrioventricular block (complete heart block and Mobitz type 2 block), 113 had DDD pacing (optimal) and none had an inappropriate mode. None of the 32 patients who had carotid sinus syndrome had an inappropriate moding system but two of the 50 patients who had sick sinus syndrome had VVI modes (inappropriate according the guidelines of $\mathrm{BPEG}^{4}$ ).

\section{COMPLICATIONS}

Major complications occurred in six (3\%) patients. These include leads displacement (four patients: three atrial leads and one ventricular lead), and wound infection which needed replacement of the pacemaker (two patients). Minor complications occurred in three patients (one patient developed small pocket haematoma within 24 hour of the procedure and further two developed a superficial wound infection that responded to antibiotics. No mortality occurred as a result of the procedures.

\section{Discussion}

This study showed that a consultant based permanent pacemaker service can be run effectively and safely in a district general hospital. Setting up such a service requires a cardiologist with good experience in dual chamber pacing and at least one highly qualified and motivated cardiac technician able to supervise the follow up and able to train other members of the team.

The implantation rate in this district general hospital was 190 per million of population per annum, which is similar to that of the UK generally (less than 200 per million of the popula- tion per annum $\left.{ }^{5}\right)$. However, this implantation rate is much less than that of Germany and Belgium, which is 450 and 600 per million respectively. ${ }^{5}$ The low implantation rate in this country is best explained by a more conservative approach to pacing in the UK. ${ }^{6}$

In this report $75 \%$ of the patients paced were more than 70 years old, similar to the age distribution in the UK $(73 \%$ of pacemaker implants are in the over $\left.70 \mathrm{~s}^{7}\right)$. Elderly patients have been shown to have the same benefit for pacemaker implantation (for example, time to ascend stairs) as has been shown in younger patients. ${ }^{8}$ There has been concern in terms of modes of pacing used in the elderly in the past: it was suggested that the elderly were given less complex pacing systems than younger patients and this has lead to allegations of ageism. ${ }^{9}$ In this report there is no evidence that the elderly were given a less complex system (see below).

Permanent pacing for complete atrioventricular block was the commonest indication in this study (45\%) and it was comparable (42\%) to that reported from a similar population. ${ }^{10}$ Untreated complete heart block has a one year and five year mortality of $50 \%$ and $75 \%-90 \%$ respectively ${ }^{11}{ }^{12}$; while survival is $70 \%-85 \%$ at five years in those paced. ${ }^{12}$

Sick sinus syndrome was responsible for $25 \%$ of patients paced in this report and it was identical to that reported from a similar district general population. ${ }^{10}$ Pacing for sick sinus syndrome is based on the association of symptoms with specific dysrrhythmia ${ }^{5}$; it effectively relieves bradycardic symptoms and can facilitate more aggressive drug treatment of tachyarrhythmias, ${ }^{13}$ but there is no evidence that pacing asymptomatic patients improves prognosis. ${ }^{14}$

Carotid sinus syndrome (asystole of three seconds or more with/without hypotension after carotid sinus massage in patients with syncope and/or falls) was responsible for $16 \%$ of patients paced in this study. This is higher than that reported nationally $(6.4 \%)^{15}$ - probably because there is an active tilt testing service in our hospital-but lower than centres with a dedicated "syncope clinic" $(23.2 \%) .^{15}$

Table 1 showed that 142 patients $(71 \%)$ were paced with the optimal recommended mode and only two ( $1 \%$ ) patients received inappropriate modes. Both patients were diagnosed to have sick sinus syndrome and they were paced with VVI modes.

Though it was not clear from the records why one of these patients received an inappropriate mode, the other patient had muscular dystrophy, which probably explains the choice of a simple moding system.

Thirty one of the 32 patients paced for carotid sinus syndrome received dual chamber pacing system as this was shown unequivocally to be superior to ventricular pacing. ${ }^{16}$

The major complications rate $(3 \%)$ was low and was comparable to that reported $(2.48 \%)$ from a district general hospital ${ }^{17}$ and similar to that reported $(2.8 \%)$ from a tertiary centre. ${ }^{18}$ Pacemaker implantation in a district general hospital reduces in-hospital stay and reduces 
the time spent with a temporary pacing system which increases the risk of septicaemia. It also reduces the need for elderly patients and relatives to travel great distances for follow up.

\section{Summary}

This report confirms the feasibility of permanent pacemaker insertion effectively in a district general hospital with a low incidence of complications. It also confirms that appropriate pacing modes can effectively be selected in this setting.

The authors thank Mrs L Miller and Mrs M Bird and all the other staff in the Cardiovascular Department at Arrowe Hospital for their help and support in preparing this report.

1 Working group of the British Cardiac Society. Cardiology in the district hospital. Br Heart F 1987;58:537-46.

2 A report of the working group of the BCS. Cardiology in the district hospital. Br Heart 7 1994;72:303-8.

3 ACC/AHA Task Force Report. Guidelines for implantation of cardiac pacemakers and antiarrhythmia devices. A report of cardiac pacemakers and antiarrhythmia devices. A report
of the American College of Cardiology/American Heart Association Task Force on Assessment of Diagnostic and Association Task Force on Assessment of Diagnostic and Pacemaker Implantation). 7 Am Coll Cardiol 1998;31:1175209.

4 BPEG working party report. Recommendations for pacemaker prescription for symptomatic bardycardia - report of a working party of the British Pacing and Electrophysiology Group. Br Heart $\mathcal{F}$ 1991;66:185-91

5 Cunningham AD, Rickards AF, Nathan AW. Trends in pacemaker implantation; is the UK the "poor man of Europe"? [abstract]. Br Heart f 1994;71(suppl):59

6 Rickards AF. Where is the block? BMf 1984;288:737-8.

7 British Pacing and Electrophysiology Group. BPEG data bulletin. Strathclyde: BPEG, 1996

8 Ray SG, Connally DT, Hughes M, et al. Stability of the DDD pacing mode in patients 80 years of age and older. PACE 1994;17:1218-21.

9 Payne GE, Skehan JD. Issues in cardiac pacing: can ageism be justified? Br Heart $\mathscr{f} 1994 ; 72: 102-3$.

10 British Pacing and Electrophysiology Group. Database. Statistics for the City General Hospital, Stoke-on-Trent. tistics for the City General

11 Johansson BW. Compete heart block. A clinical hemodynamic and pharmacological study in patients with and without an artificial pacemaker. Acta Medica Scandinavica 1966; 180(suppl): 451

12 Alpert MA, Curtis JJ, Sanfelippo JF, et al. Comparative survival after permanent ventricular and dual chamber pacin for patients with chronic high degree atrioventricular block with and without pre-existent congestive heart failure. $7 \mathrm{Am}$ Coll Cardiol 1986;7:925-32.

13 Rasmussen K. Chronic sinus node disease: natural course and indications for pacing. Eur Heart f 1981;2:455-9.

14 Shaw DB, Holmann RR, Gower JI. Survival in sinoatrial disease (sick sinus syndrome). BMF 1980;280:139.

15 Dey AB, Dexton RS, Tyman MM, et al. The impact of a dedicated "syncope and falls" clinic on pacing practice in dedicated "syncope and falls" clinic on pacing
Northeastern England. PACE 1997;20:815-17.

16 Bringole $M$, Menozzi C, Lolli $G$, et al. Validation of a method for choice of pacing mode in carotid sinus syndrome with and without sinus bardycardia. PACE 1991; 13:196-203.

17 Doherty JG, Dawson F, Kerr F. Permanent pacemaker practice at a Scottish district general hospital between 1987 and 1993. Br Heart $\mathcal{F}$ 1995;73:475-8.

18 Mugica J, Ritter P, Lazarus B, et al. Evaluation of early complications after ventricular single chamber pacemaker implants in a specialist centre: 9483 patients over 24 years. Eur $\mathcal{F}$ Cardiac Pacing Electrophysiol 1993;3:21-6.

19 Berntein A, Camm J, Fletcher R, et al. The NASPE/BPEG generic pacing code for antibradyarrhythmia and adaptive rate pacing and antitachycardia devices. PACE 1987;10: 794-9.

\section{Appendix 1}

NASPE/BPEG PACEMAKER GENERIC CODE ${ }^{19}$

Examples: AAI, VVI, DDDR

- First letter signifies the chamber(s) being paced:

A (atrium)

$\mathrm{V}$ (ventricle)

$\mathrm{D}$ (atrium and ventricle)

- Second letter indicates the chamber(s) being sensed:

A (atrium)

$\mathrm{V}$ (ventricle)

$\mathrm{D}$ (atrium and ventricle)

- Third letter indicates the mode of sensing: I (inhibited)

$\mathrm{T}$ (triggered)

$\mathrm{D}$ (inhibited and triggered)

- Fourth letter indicates rate responsiveness: $\mathrm{O}$ (none)

$\mathrm{R}$ (rate responsiveness).

- Fifth letter indicates:

Antitachycardiac device

\section{Appendix 2}

GUIDELINES AND GENERAL PRINCIPLES FOR PERMANENT PACEMAKER INSERTION ${ }^{4}$

\section{(A) Guidelines}

Patients considered for pacing are divided into three groups:

- Class 1: Conditions in which there is general agreement that pacemakers should be implanted-syncopal patients with complete heart block or prolonged sinus arrest.

- Class 2: Conditions in which permanent pacemakers are frequently used but there is some divergence of opinion about whether they are needed-sick sinus syndrome without syncope but with other symptoms.

- Class 3: Conditions in which there is general agreement that pacemaker are not needed-asymptomatic patients with sinus node disease or first degree atrioventricular block and unexplained syncope without obvious cardiac arrhythmia.

(B) General principles for pacemaker choice

(1) The ventricle should be paced if there is actual or threatened AB block.

(2) The atrium should be paced/sensed unless contraindicated.

(3) Rate response is not essential if the patient is inactive or has a normal chronotropic response. 